
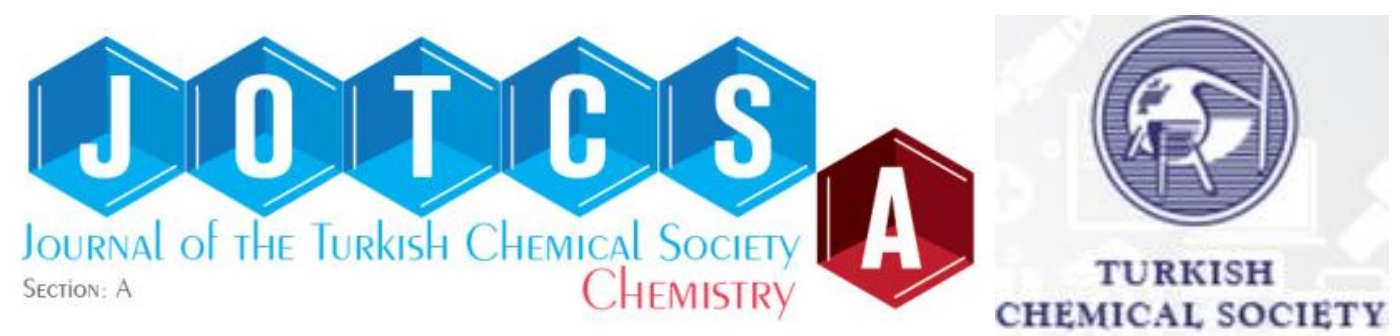

\title{
Comparison of the Quality Properties of Some Commercial Cold pressed Seed Oils
}

\author{
Vasfiye Hazal ÖZYURT ${ }^{1 *}$ (D)
}

${ }^{1}$ Near East University, Faculty of Engineering, Department of Food Engineering, 99138 Nicosia, Mersin 10, TRNC, Turkey.

Abstract: In this study, the aim is to explain some quality properties of five different kinds of seed oils produced by the cold pressed extraction method. Coffee bean, pomegranate seed, cherry seed, apricot seed, and fig kernel cold pressed oils that are produced in the domestic market of Turkey were evaluated in terms of their some quality characteristics such as peroxide values, free fatty acidity, and UV-specific extinction values, total phenolic compounds and antioxidant activity. The highest levels of peroxide values and free fatty acid values were determined in coffee bean oil with abundances of $26.34 \mathrm{mEqO} / \mathrm{kg}$ oil and 2.07 $\mathrm{mg} \mathrm{KOH} / \mathrm{g}$ oil, respectively. Coffee bean oil also had relatively high UV-specific extinction values (K232 values 4.04 and K270 values 3.99 ). In the results of the total phenolic compound analysis performed to recognize the effects on health, this value was highest in coffee bean oil, with $1380 \mathrm{mg}$ GAE/L oil. The results of the highest antioxidant activity were examined in the fig kernel oil. These values were compared with the studies in the literature and evaluated according to the legal boundaries.

Keywords: cold pressed oils, seed oil, total phenolic content, ABTS.

Submitted: December 13, 2018. Accepted: March 25, 2019.

Cite this: Özyurt VH. Comparison of the Quality Properties of Some Commercial Cold pressed Seed Oils. JOTCSA. 2019;6(2):149-56.

DOI: https://dx.doi.org/10.18596/jotcsa.496458.

*Corresponding author. E-mail: hazal.ozyurt@gmail.com; hazal.ozyurt@neu.edu.tr.

\section{INTRODUCTION}

Seeds are industrial by-products and large amounts of these by-products are generated as waste after fruit processing. They are rich in macromolecules including carbohydrates, oils, and proteins as well as phytochemicals including phenolic compounds, vitamins, and minerals etc. (1). Due to their low economic value, seeds are generally used as animal feed or fuel (2) and they create significant environmental pollution (3). However, in recent years, they have attracted significantly more attention due to their usage as an extraction source for the production of invaluable phytochemicals such as dietary fiber, phenolic compounds and anthocyanin $(3,4)$. There have been numerous reports including the chemical composition of seeds and their phytochemical contents (5-8) and their economic values in terms of these components (3). It is known that their phytochemical contents such as antioxidant compounds and vitamins have positive effects on human health due to their preservation effects regarding deterioration, rancidity or discoloration in food (5). Seed oils are also used in the cosmetics and pharmaceutical industries. There are several studies about the functional and medicinal effects of seed oils such as antioxidant $(9,10)$ and anticancer activity $(11,12)$, antidiabetic and anti-obesity effects (13), protective effect against atherosclerosis, antiinflammatory activity, immune function 
modulation, etc. (14). Moreover, these oils are often available as raw materials for use in the food industry.

Cold pressing (mechanical pressing) is a seed oil production technology that does not need heat treatment or solvent extraction. Moreover, this technology is cost-effective, less labor-intensive, safer, simpler and more ecologically friendly than other oil extraction procedures (15). Seed oils are not refined and for that reason, they contain lipophilic phytochemicals (6). Since cold pressing does not require much energy, this process is considerably beneficial for small and medium scale companies. Therefore, there has been increased interest in cold pressing due to the benefits such as the nutritive properties of the seed oils and low costs (16).

The main object of this study was to give an overview of general quality parameters including peroxide values, free fatty acidy, UV-specific extinction, total phenolic content and antioxidant activity of the less studied cold pressed seed oils sold on the market on the grounds that they have beneficial effects on health.

\section{MATERIAL AND METHODS}

\section{Materials}

All chemicals and reagents were analytical grade and were purchased from Sigma Aldrich Chemical Co. (Steinheim, Germany) and Merck (Darmstadt, Germany). The coffee bean oil (CBO), pomegranate seed oil (PSO), cherry seed oil (CSO), apricot seed oil (ASO) and fig kernel oil (FKO) were donated by a local manufacturer (Zade Vital Pharmaceuticals Inc.). The seeds were supplied by a supplier in Konya, Turkey. The samples were approved after the relevant quality control analyses. The origins of the seeds were Brazil, Manisa, Gaziantep, Malatya and Izmir for CBO, PSO, CSO, ASO and FKO, respectively. According to the manufacturer's definition, the oils were produced by cold pressing at an industrial scale (200 kg seed/day capacity, single head, $2.2 \mathrm{~kW}$ power). The cold pressing procedure was set by a $10-\mathrm{mm}$ exit die, with a screw rotation speed of $40 \mathrm{rpm}$, and an exit temperature of $40{ }^{\circ} \mathrm{C}$. After pressing, the oils were kept at $4{ }^{\circ} \mathrm{C}$ until needed for analysis.

\section{Methods \\ Determination of peroxide value (PV)}

Peroxide value was determined according to the Official Methods of American Oil Chemists' Society (AOCS) Cd 8-53. $0.5 \mathrm{~g}$ of seed oil was mixed with $3 \mathrm{~mL}$ of acetic acid:chloroform solution (3:2, v/v). Then, saturated potassium iodide (KI) solution was added to the mixture and shaken constantly for $1 \mathrm{~min}$. After the solution was diluted with Milli-Q water ( $3 \mathrm{~mL}), 0.01$ $\mathrm{N}$ standardized sodium thiosulfate solution was used in the titration. Titration was ceased when the yellow iodine color just disappeared. After titration, $0.2 \mathrm{~mL}$ of starch solution ( $1 \mathrm{~g} / 100 \mathrm{~mL}$ ) was added and titration continued until the blue color disappeared (17). Peroxide value was calculated using the formula below:

$$
P V\left(m E q O_{2} / k g \text { oil }\right)=\frac{S x N \times 1000}{\text { Weight of oil }(g)}
$$

where $S$ is the volume of standardized sodium thiosulfate solution (Sample or Blank) and $\mathrm{N}$ is the normality of standardized sodium thiosulfate solution.

\section{Determination of Free Fatty Acid value (FFA)}

Free fatty acid values of samples were determined according to AOCS Cd 3d-63. To prepare the neutralized alcohol solution, $1 \mathrm{~g}$ of the oil, $1.25 \mathrm{~mL}$ of pure ethanol, and $50 \mu \mathrm{L}$ of phenolphthalein were heated at $60^{\circ} \mathrm{C}$ in a water bath with constant shaking. Then, the mixture was titrated with adequate $0.01 \mathrm{~N} \mathrm{NaOH}$ until a pink color appeared. This neutralized alcoholic solution was mixed with an additional $1.41 \mathrm{~g}$ of seed oil and one more titration was carried out with $0.01 \mathrm{~N} \mathrm{NaOH}$ (18). The free fatty acid value was calculated using the formula below:

$$
\text { Acid value }(m g \mathrm{KOH} / \mathrm{g})=\frac{V x 56.1 \times N}{E}
$$

where $\mathrm{V}$ is the consumed volume of the titrant in $\mathrm{mL}, \mathrm{N}$ is the normality of titrant, and $\mathrm{E}$ is the sample weight in $\mathrm{g}$.

\section{Measurement of specific extinction values}

Specific extinction values of seed oils at the wavelengths of 232 and $270 \mathrm{~nm}$ were determined according to the IUPAC method II.D.23. Seed oils were diluted in cyclohexane $(1: 100)$ using the method by Choo et al. (2007) (8). Samples were measured on a Varian Cary 50 Bio UV-Vis spectrophotometer using $1 \mathrm{~cm}$ path length quartz cuvettes with solvent as blank. 


\section{Determination of total phenolic contents (TPC)}

Total phenolic contents were determined using the Folin-Ciocalteu colorimetric method with slight modifications to the reference (19). The calibration curve was drawn with the gallic acid solutions (0$1000 \mathrm{mg} / \mathrm{L}$ ). The results were expressed as $\mathrm{mg}$ of gallic acid equivalents per liter of seed oil sample (mg GAE/L oil). An aliquot $(50 \mu \mathrm{L})$ of the seed oil was placed in a volumetric flask $(5 \mathrm{~mL})$. Diluted FolinCiocalteu reagent $(25 \mu \mathrm{L})$ was added. After 5 min, saturated sodium carbonate (75 $\mu \mathrm{L}$ ) was added. The flask was filled with water up to $5 \mathrm{~mL}$. After $2 \mathrm{~h}$, absorbance at $765 \mathrm{~nm}$ against a reagent blank was measured using a UV-Vis spectrophotometer.

\section{ABTS assay of total antioxidant activity}

Firstly, ABTS radical was prepared as 7 $\mathrm{mM}$ ABTS water solutions and $2.45 \mathrm{mM}$ potassium persulfate (1:0.5 ratio, $v: v)$, which were mixed and diluted by ethanol until the absorbance (at $734 \mathrm{~nm}$ ) was 0.70 . Then, $1 \mathrm{~mL}$ of ABTS radical was added into $20 \mu \mathrm{L}$ of sample. The absorbance was read at $734 \mathrm{~nm}$. The results were given as Trolox equivalent (20).

\section{Statistical analysis}

All statistical comparisons were based on triplicate results, and data are presented as mean and standard deviation. In order to investigate differences in the seed oils, one-way ANOVA with Tukey's post-test was used. Data were analyzed with SPSS 10.0 .

\section{RESULTS AND DISCUSSION}

Table 1 shows a summary of the peroxide values, free fatty acidity and UV-specific absorption values, total phenolic compounds and antioxidant activity of five cold pressed seed oils.

Peroxide value is the amount of lipid peroxides found in the oil samples (21). Lipid peroxides are the primary products of lipid oxidation. The types and amounts of these components vary according to the position and number of double bonds in unsaturated fatty acids found in oils (22). According to Turkish Food Codex (TFC) No: $2012 / 29$, maximum peroxide values of refined vegetable oils can be recommended as $10 \mathrm{mEq} \mathrm{O}_{2} / \mathrm{kg}$ oil and this value is $15 \mathrm{mEq} \mathrm{O} / \mathrm{kg}$ oil for cold pressed oil and natural oils. On the other hand, according to TFC No: 2017/26, in natural olive oil, the acceptable minimum for the peroxide value is from $20 \mathrm{mEq}$ $\mathrm{O}_{2} / \mathrm{kg}$ oil. The Codex Alimentarius Commission (1999) states that the PV in refined vegetable oils should not be higher than $10 \mathrm{mEq} \mathrm{O} / 2 / \mathrm{kg}$ oil, and for cold pressed and virgin oils, it should not be higher than $15 \mathrm{mEq} \mathrm{O}_{2} / \mathrm{kg}$ oil. Based on this information, pomegranate seed oil showed a peroxide value lower than the recommended upper limit. Içyer et al. (2017) evaluated the PV of fig kernel oil in Turkey as $3.70 \mathrm{mEq} \mathrm{O} / \mathrm{kg}$ oil (23). Shariatifar et al. (2017) (24) found a PV between 0.35 and $1.9 \mathrm{mEq} \mathrm{O}_{2} / \mathrm{kg}$ oil in apricot seed oils from Iran. Khoddami et al. 2014 (25) characterized the pomegranate seed oils sold in Iran and Turkey and found the PV to be 4.70-6.23 $70 \mathrm{mEq} \mathrm{O} / \mathrm{kg}$ oil (25). Anese et al. (2000) (26) compared the effect of coffee roasting on the PV of coffee seeds. The PV of all coffee samples were found to be approximately $7 \mathrm{mEq} \mathrm{O}_{2} / \mathrm{kg}$ oil. Popa et al. (2011) (27) found the PV of sour cherry seed oils from Banat, Romania as $1.6 \mathrm{mEq}$ $\mathrm{O}_{2} / \mathrm{kg}$ oil. In our study, the PVs were found to be higher than the regulations and previous studies, except for PSO. This may be an indication that the temperature increased or the extraction duration extended during the cold pressing procedure and therefore, the oxidation of the oil sample was processed.

The number of FFA is another important parameter in the determination of the quality of seed oil (17). The number of FFA in a product can also vary according to the number of peroxides. According to TFC 2012/29, all the seed oils showed lower acid values than the acceptable maximum level. When these seed oils were compared to olive oils (TFC 2017/26), higher acid values were observed. The free fatty acid value is related with the lipase activity and hydrolysis of triacylglycerols in the seed (25). This amount of acid value is directly related with the consumption of oil. When this value is lower, the oil is suitable for consumption and long-term storage. The free fatty acid value of sour cherry seed oil from Romania was found to be $1 \mathrm{mg}$ $\mathrm{KOH} / \mathrm{g}$ oil (27). Yılmaz et al. (2018) reported the acid value of sour cherry seed oil from Mersin, Turkey to be 1.45 $\mathrm{mg} \mathrm{KOH} / \mathrm{g}$ oil (4). İcyer et al (2017) (23) determined the acidity of fig kernel oils from Turkey as $0.95 \%$ of oleic acid. Amri et al. (2017) (28) found the acidity value of pomegranate seed oil from Mahdia, 
Tunisia as $1.69 \%$ of oleic acid. Özcan et al (2010) (29) evaluated the acid value of different brands of apricot kernel oil and detected between 0.3 and $1.56 \%$ of oleic acid. In this study, the five cold pressed oils were found to have lower free fatty acidity than the Codex Alimentarius Commission (1999).

There have been several studies that have determined the specific absorption value of cold pressed oils. The $\mathrm{K}_{232}$ value represents primary oxidation products (hydroperoxides), while the $K_{270}$ value indicates secondary oxidation products (odor and aroma components). Undesirable odor components resulting from oxidation are due to secondary oxidation products formed as a result of the breakdown of peroxides. The specific absorbance values at 232 and $270 \mathrm{~nm}$ of the five cold pressed seed oils are shown in Table 1. The results of this analysis are comparable to the peroxide values. There is no value in TFC $2012 / 29$ to compare these cold pressed seed oils. However, for $\mathrm{K}_{232}$, the acceptable upper limit is 2.5 and for 270, it is 0.22 in TFC $2017 / 26$. Within the knowledge of the author, there is no study in literature about the specific extinction values of these cold pressed seed oils.

Phenolic substances are important food components that are known to be the cause of enzymatic color changes in foods, having antioxidant properties (30) and may protect lipids from peroxidation (6). Although a large number of phenolic compounds are water-soluble, a small amount might be found in oil (31). Cold pressed seed oils differ in their total phenolic contents, which varied from 444.00 to $1390.20 \mathrm{mg}$ GAE per liter of oil. These findings are in agreement with literature data. The total phenolic contents of soybean, sunflower, rapeseed, corn, grapeseed, hemp, flax, rice bran, and pumpkin were evaluated and the results were found to be between 0.51 and $2.46 \mathrm{mg}$ caffeic acid equivalent $/ 100 \mathrm{~g}$ of oil (5). Jorge et al. (2016) detected the amount of total phenolic compound of orange seed oil as $4.43 \mathrm{~g} / \mathrm{kg}$ (32). Yılmaz and Gökmen (2013) (33) applied different extraction conditions to determine the total phenolic content of sour cherry seed oil and found the total phenolic content to be between 6.60 and $27.87 \mathrm{mg}$ gallic acid equivalent (GAE) per $L$ of oil. Parry et al. (2005) evaluated the amount of total phenolic content for cold pressed berry seed oils and the values were found to be
1.73-2.0 mg GAE/g sample (34). To further confirm the antioxidant properties of cold pressed seed oils, ABTS $^{+}$radical scavenging activity, which is one of the most commonly used methods, was evaluated (35). Different antioxidant activity methods were developed due to the complexity of the oxidation processes, such as DPPH, ABTS radical scavenging activity, oxygen radical absorbance capacity (ORAC), cupric ion reducing antioxidant capacity (CUPRAC) $(36,37)$ etc. Each of these analyses measures the antioxidant activity from a different perspective (38). The principle of ABTS radical scavenging activity is that colorful cation radicals of $\mathrm{ABTS}^{+}$are used (37). Santos et al. (2017) determined the antioxidant activity by using the ABTS method for favela seed oils as $3.83 \mathrm{mmol}$ Trolox/kg oil (39). In another study, the antioxidant activity of cactus pear seed oils was evaluated and found a value of $66.35 \mathrm{mg}$ ascorbic acid equivalent per 100 $\mathrm{g}$ of oil (40). Castelo-Branco and Torres (2012) explained that this antioxidant activity is dependent on the lipophilic fraction of samples (41). The seed oils used in this study have not been investigated in terms of phenolic compounds and antioxidant activity. When these five cold pressed seed oils were compared with each other, differences were observed and the reason for these differences could be the growing conditions of plant, the seed variety, seed and oil storage conditions and processing (6). For that reason, $\mathrm{ABTS}^{+}$antioxidant radical scavenging activities of the five cold pressed seed oils were compared with other cold pressed seed oils in the literature. Therefore, these five cold pressed seed oils might also serve as a rich source of phenolic antioxidants and occur as a stable oil under oxidative conditions such as storage, heat and light. 
Table 1: The quality properties of commercial cold pressed seed oils.

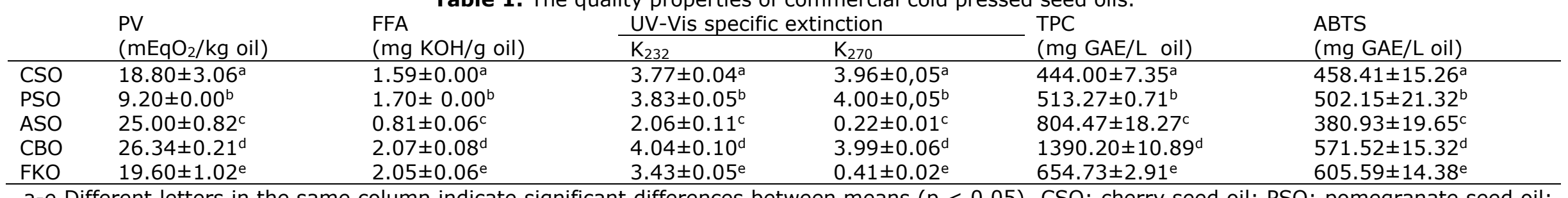

a-e Different letters in the same column indicate significant differences between means ( $<$ < 0.05). CSO: cherry seed oil; PSO: pomegranate seed oil: ASO: apricot seed oil; CBO: coffee bean oil; FKO: fig kernel oil; PV: peroxide value; FFA: free fatty acid; TPC: total phenolic content; ABTS: Antioxidant activity. 


\section{CONCLUSION}

In this study, five cold pressed seed oils were researched to determine whether they have generally similar characteristic properties and were compared according to the above-mentioned regulations and literature. The characteristic properties of these cold pressed seed oils are important in terms of the quality of the oil as well as the amount of total phenolic content, while the antioxidant activity of these seed oils has an influence on the health effect. However, since the effects of processing, packaging, and storage of the oils were not taken into consideration, some of the quality properties of the oils would be lost. According to the total phenolic content and antioxidant activity results obtained from this study, the cold pressed seed oils have the potential to protect macromolecules from free radical attacks and oxidative damage caused by radicals. The studied cold pressed seed oils have received minimal focus and there is limited data in the literature about these oils. This study increases the understanding of the character and quality of cold pressed seed oils and may also be a baseline for developing regulations for cold pressed seed oils.

\section{ACKNOWLEDGEMENT}

The author thanks ZADE VITAL Pharmaceuticals Inc. for providing cold pressed seed oils. This study was presented as an oral presentation at the 30. National Chemistry Congress, 5-8 November 2018, Kaya Artemis Resort Hotel, Gazimagusa, TRNC.

\section{CONFLICT OF INTEREST}

The authors declare that there is no conflict of interest.

\section{FINANCIAL DISCLOSURE}

The author declared that this study has received no financial support.

\section{REFERENCES}

1. Talekar S, Patti AF, Singh R, Vijayraghavan R, Arora A. From waste to wealth: High recovery of nutraceuticals from pomegranate seed waste using a green extraction process. Ind Crops Prod. 2018;112:790-802.

2. Ozyurt VH, Otles S. Hazelnut testa as a by-product: nutritional composition, antioxidant activity, phenolic compound profile and dietary fiber content. J Fac Pharm Ankara Univ. 2018;42(3):38-57.

3. Peschel W, Sánchez-Rabaneda F, Diekmann W, Plescher A, Gartzía I, Jiménez $D$, Lamuela-Raventos $\mathrm{R}$, Buxaderas S, Codina, C. An industrial approach in the search of natural antioxidants from vegetable and fruit wastes. Food Chem. 2006;97(1):137-50.

4. Yılmaz FM, Görgüç A, Karaaslan $M$, Vardin $H$, Ersus Bilek $S$, Uygun Ö, Bircan C, Sour Cherry Byproducts: Compositions, Functional Properties and Recovery Potentials - A Review. Crit Rev Food Sci Nutr. 2018;0(0):1-

5. Siger A, Nogala-Kalucka M, Lampart-Szczapa E. The Content and Antioxidant activity of phenolic Compounds in Cold pressed Plant Oils. J Food Lipids. 2008;15:137-49.

6. Lutterodt $H$, Luther $M$, Slavin $M$, Yin JJ, Parry J, Gao JM, Yu L. Fatty acid profile, thymoquinone content, oxidative stability, and antioxidant properties of cold pressed black cumin seed oils. LWT - Food Sci Technol [Internet]. 2010;43(9):1409-13.

7. Yilmaz E, Sevgi Arsunar E, Aydeniz B, Güneşer O. Cold pressed capia pepperseed (Capsicum Annuum L.) oils: Composition, aroma, and sensory properties. Eur J Lipid Sci Technol. 2015;117(7):1016-26.

8. Choo WS, Birch J, Dufour JP. Physicochemical and quality characteristics of cold pressed flaxseed oils. J Food Compos Anal. 2007;20(3-4):202-11.

9. Gustinelli G, Eliasson L, Svelander $C$, Alminger M, Ahrné L. Supercritical CO2 extraction of bilberry (Vaccinium myrtillus L.) seed oil: Fatty acid composition and antioxidant activity. J Supercrit Fluids. 2018;135(January):91-7. 
10. Chang S, Bassiri A, Jalali H. Evaluation of Antioxidant Activity of Fennel ( Foeniculum vulgare ) Seed Extract on Oxidative Stability of Olive Oil. J Chem Heal Risks. 2013;3(2):53-61.

11. Eswaramkunnath J. Omega Fatty Acids in Prostate Cancer - A Review. Indian J Pharm Pract. 2018;11(2):64-6.

12. Ren $P$, Ren $X$, Cheng $L, X u L$. Frankincense, pine needle and geranium essential oils suppress tumor progression through the regulation of the $A M P K / m T O R$ pathway in breast cancer. Oncol Rep. 2018;39(1):129-37.

13. Wang $\mathrm{F}$, Li $\mathrm{H}$, Zhao $\mathrm{H}$, Zhang $\mathrm{Y}$, Qiu P, Li J, et al. Antidiabetic Activity and Chemical Composition of Sanbai Melon Seed Oil. Evidence-based Complement Altern Med. 2018;1-14.

14. Aruna P, Venkataramanamma D, Singh AK, Singh RP. Health Benefits of Punicic Acid: A Review. Compr Rev Food Sci Food Saf. 2016;15(1):16-27.

15. Celenk V, Gumus ZP, Ustun Argon $Z$, Buyukhelvacigil M, Karasulu E. Analysis of Chemical Compositions of 15 Different Cold pressed Oils Produced in Turkey : A Case Study of Tocopherol and Fatty Acid Analysis. JOTCSA. 2018;5(1):118.

16. Thanonkaew A, Wongyai S, McClements DJ, Decker EA. Effect of stabilization of rice bran by domestic heating on mechanical extraction yield, quality, and antioxidant properties of cold pressed rice bran oil (Oryza saltiva L.). LWT - Food Sci Technol [Internet]. 2012;48(2):231-6.

17. Costa AMM, Silva LO, Torres AG. Chemical composition of commercial cold pressed pomegranate (Punica granatum) seed oil from Turkey and Israel, and the use of bioactive compounds for samples' origin preliminary discrimination. J Food Compos Anal. 2019;75:8-16.

18. Sun-Waterhouse D, Zhou J,
Miskelly GM, Wibisono R, Wadhwa SS. Stability of encapsulated olive oil in the presence of caffeic acid. Food Chem. 2011;126(3):104956.

19. Singleton VL, Rossi JA, Jr J. Colorimetry of Total Phenolics with Acid Reagents. Am J Enol Vitic. 1965;16:144-158.

20. Re R, Pellegrini N, Proteggente A, Pannala A, Yang M, Rice-Evans C. Antioxidant Activity Applying an Improved Abts Radical Cation Decolarization Assay. 1999;26:1231-7.

21. Kasote DM, Badhe YS, Hegde M V. Effect of mechanical press oil extraction processing on quality of linseed oil. Ind Crops Prod. 2013;42(1):10-3.

22. Mokhtar SM, Swailam HM, Embaby HES. Physicochemical properties, nutritional value and techno-functional properties of goldenberry (Physalis peruviana) waste powder concise title: Composition of goldenberry juice waste. Food Chem. 2018;248:17.

23. Icyer NC, Toker OS, Karasu S, Tornuk F, Kahyaoglu T, Arici M. Microencapsulation of fig seed oil rich in polyunsaturated fatty acids by spray drying. J Food Meas Charact. 2017;11(1):50-7.

24. Shariatifar N, Pourfard IM, Khaniki G], Nabizadeh R, Akbarzadeh A, Nejad ASM. Mineral Composition, Physico-chemical Properties and Fatty Acids Profile of Prunus armeniaca Apricot Seed Oil. Asian J Chem. 2017;29(9):2011-5.

25. Khoddami A, Man YBC, Roberts TH. Physico-chemical properties and fatty acid profile of seed oils from pomegranate (Punica granatum L.) extracted by cold pressing. Eur J Lipid Sci Technol. 2014;116(5):553-62.

26. Anese M, De Pillp T, Massinf R, Lericp CR. Oxidative Stability of the Lipid Fraction in Roasted Coffee. Ital J Food Sci. 2000;4(12):457-62. 
27. Popa V, Misca C, Bordean D, Raba D, Stef D, Dumbrava D.

Characterization of sour cherries ( Prunus cerasus ) kernel oil cultivars from Banat. J Agroaliment Process Technol. 2011;17(4):398-401.

28. Amri Z, Lazreg-Aref $\mathrm{H}$, Mekni M, El-Gharbi S, Dabbaghi O, Mechri $B$, et al. Oil characterization and lipids class composition of pomegranate seeds. Biomed Res Int. $2017 ; 2017: 8-15$.

29. Özcan MM, Özalp C, Ünver A, Arslan D, Dursun N. Properties of Apricot Kernel and Oils as Fruit Juice Processing Waste. Food Nutr Sci. 2010;01(02):31-7.

30. Balasundram N, Sundram K, Samman S. Phenolic compounds in plants and agri-industrial byproducts: Antioxidant activity, occurrence, and potential uses. Food Chem. 2006;99(1):191-203.

31. Maier T, Schieber A, Kammerer DR, Carle R. Residues of grape (Vitis vinifera L.) seed oil production as a valuable source of phenolic antioxidants. Food Chem. 2009;112(3):551-9.

32. Jorge N, Da Silva AC, Aranha CPM. Antioxidant activity of oils extracted from orange (Citrus sinensis) seeds. Int News Fats, Oils Relat Mater. 2017;28(6):236.

33. Yilmaz C, Gökmen V. Compositional characteristics of sour cherry kernel and its oil as influenced by different extraction and roasting conditions. Ind Crops Prod. 2013;49:130-5.

34. Parry J, Su L, Luther M, Zhou K, Peter Yurawecz M, Whittaker $P$, et al. Fatty acid composition and antioxidant properties of cold pressed marionberry, boysenberry, red raspberry, and blueberry seed oils. J Agric Food Chem. 2005;53(3):566-73.

35. Parsons B. Antioxidants in Food: The Significance of Characterisation, Identification, Chemical and Biological Assays in Determining the Role of
Antioxidants in Food. Foods. 2017;6(8):68.

36. Apak R, Güçlü K, Özyürek M, Çelik SE. Mechanism of antioxidant capacity assays and the CUPRAC (cupric ion reducing antioxidant capacity) assay. Microchim Acta. 2008;160(4):413-9.

37. Apak R, Özyürek M, Güçlü $K$, Çapanoglu E. Antioxidant activity/capacity measurement. 1 . Classification, physicochemical principles, mechanisms, and electron transfer (ET)-based assays. J Agric Food Chem. 2016;64(5):997-1027.

38. Juárez-Trujillo $\mathrm{N}$, MonribotVillanueva JL, Alvarado-Olivarez $M$, Luna-Solano G, GuerreroAnalco JA, Jiménez-Fernández $M$. Phenolic profile and antioxidative properties of pulp and seeds of Randia monantha Benth. Ind Crops Prod. 2018;124:53-8.

39. Santos KA, Filho OPA, Aguiar CM, Milinsk MC, Sampaio SC, Palú F, et al. Chemical composition, antioxidant activity and thermal analysis of oil extracted from favela (Cnidoscolus quercifolius) seeds. Ind Crops Prod. 2017;97:368-73.

40. Ortega-Ortega $M$ de los A, CruzCansino N del S, Alanís-García E, Delgado-Olivares L, Ariza-Ortega JA, Amírezmoreno ER, et al. Optimization of ultrasound extraction of cactus pear (Opuntia ficus indica) seed oil based on antioxidant activity and evaluation of its antimicrobial activity. J Food Qual. 2017;1-9.

41. Castelo-Branco VN, Torres AG. Generalized linear model describes determinants of total antioxidant capacity of refined vegetable oils. Eur J Lipid Sci Technol. 2012;114(3):332-42. 